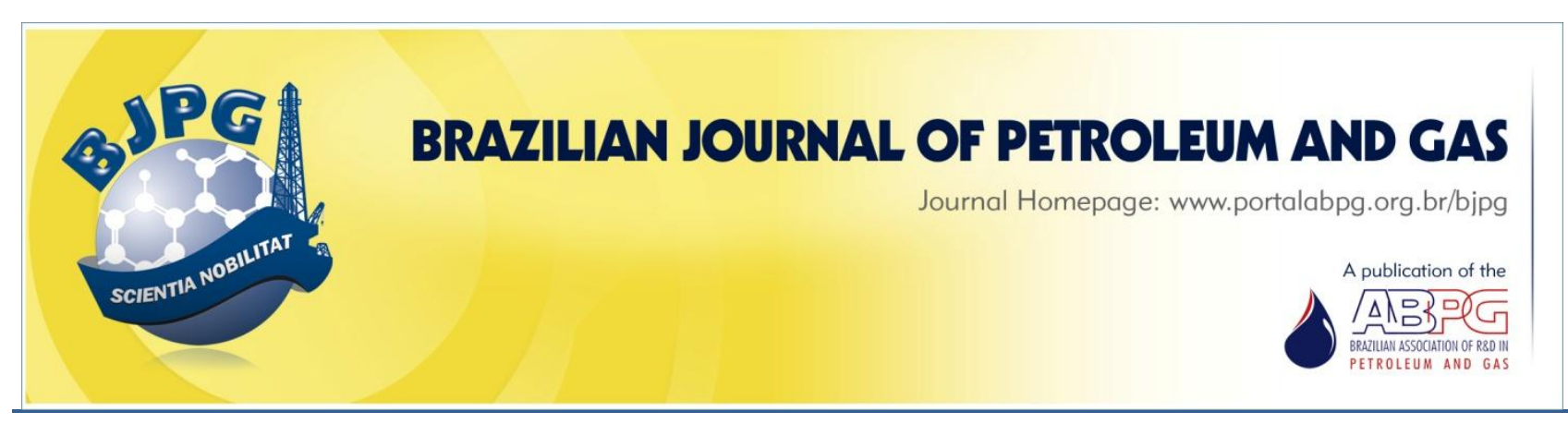

\title{
NEW METHODOLOGY FOR GAS MIGRATION PREDICTION BEFORE OILWELL CEMENTING
}

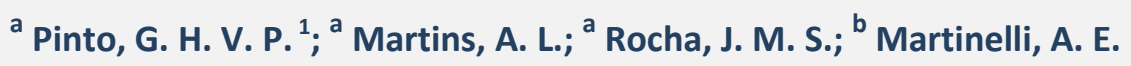

${ }^{\text {a }}$ Petróleo Brasileiro S.A., Salvador, Brazil

b Universidade Federal do Rio Grande do Norte, Natal, Brazil

\begin{abstract}
Many challenges have been presented in oil well drilling including preventing gas migration after cementing operations. This phenomenon is potentially dangerous since the gas can migrate to the surface causing the annular pressurization or lead to a blowout with catastrophic results that may include the loss of the well. If the hydrostatic pressure in front of the gas zone becomes lower than the pressure in this zone, the gas will invade the well. This work presents a comprehensive methodology to evaluate gas migration after cementing operations taking into account the critical static gel strength concept associated with time dependent viscosity behavior. A mechanistic model based on a force balance acting on gas bubble was proposed to predict the bubble displacement through the cement slurry while it gels and evaluate if the hydraulic isolation will be affected allowing project operation changes to ensure well construction safely.
\end{abstract}

\section{KEYWORDS}

cementing; gas migration; rheology; gel strength

\footnotetext{
${ }^{1}$ To whom all correspondence should be addressed.

Address: Petrobras, Tenente Fernando Tuy Street, 56, Pituba, Salvador, Brazil | Zip code: 41830-498

Telephone: +55 71 8120-8797 | E-mail: gustavo cep@yahoo.com.br

doi:10.5419/bjpg2012-0006
} 


\section{INTRODUCTION}

Cementing operations are very important to well construction. Any procedural flaw may require corrections which in many cases are difficult to achieve. One of the main functions of the cement slurry is the hydraulic isolation between zones containing fluids. This is achieved when the annular space between the casing and formation is completely filled with cement slurry with optimized properties.

To improve the displacement efficiency is necessary good casing centralization and drilling fluid treatment to reduce the slurry' rheological properties and improve its removal. Other actions that facilitate the removal process and can be implemented are: pipe movement, achieved by either rotating or reciprocating (alternating cycles of vertical movement); usage of rubber plugs inside the casing to separate mechanically the fluids involved; and pumping of chemically compatible and optimized fluids to separate the drilling fluid from the cement slurry preventing its contamination.

If the drilling fluid displacement by cement slurry is not efficient it will create a fluid channel formed by the remaining fluid that intercommunicate two zones damaging the hydraulic isolation as shown in Figure 1.

Even if all case positioning procedures and annular space cleaning through efficient drilling fluid removal have been made, there are other processes that take place during the cement setting that can influence the perfect hydraulic

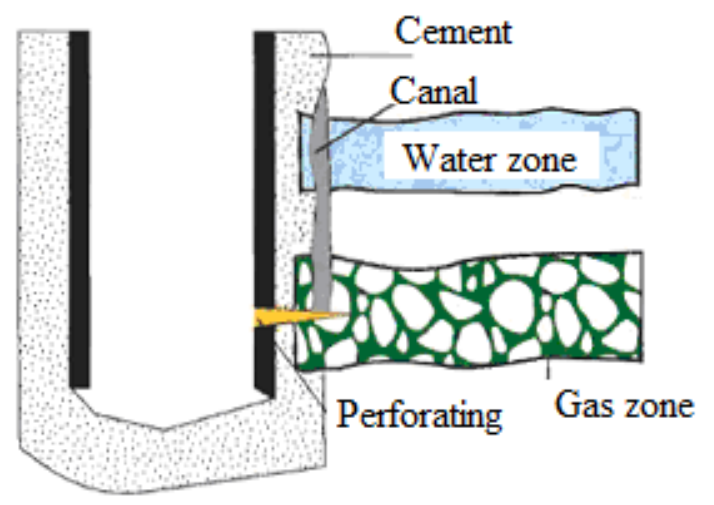

Figure 1. Canalization generated by inefficient displacement of drilling fluid (modified from Nelson and Guillot, 2006). isolation. The methodology developed in this study discusses the applications of these other processes.

\section{CHANGES THAT OCCUR IN THE CEMENT SLURRY}

The cement slurry physical state progresses from a liquid immediately after its positioning in the well, transmitting its hydrostatic pressure, to a gel after a certain time under static conditions. Cement particles create cohesive structures that support part of its weight getting the initial fluid hydrostatic pressure trapped within the cement pore matrix.

The main factor controlling the pore pressure of the permeable interval becomes the pore pressure within the cement matrix and, since this pressure is greater than the pore zone (e.g., the gas zone), this gas will not be able to invade this structure. However, the pore pressure within the cement matrix is a function of its water volume and its reduction corresponds to the pore pressure reduction allowing the gas invasion. The fluid-loss can occur in two main ways: the cement hydration and the loss of fluid to the zone (Cheung and Beirute, 1985).

\section{ADDITIVES FOR OIL WELL CEMENTING}

The cement slurry should be designed to provide optimized physical and chemical properties both in liquid and solid state. In the liquid state, the cement slurry should have density and rheological properties that meet operational window and drilling fluid replacement requirements. Also, it has to present a thickening time that is long enough to complete the pumping operation to the desired position in the well and the resistance development within the time required to resume operation. In addition, the cement slurry must have fluid-loss control and be resistant to fluids migration such as water and gas. In the solid state, it needs to have low permeability and be resistant to downhole conditions such as pressure and temperature (Rocha, 2010).

Gas migration can be avoided in many ways. The first step is to optimize the removal process and, in parallel, optimize the cement slurry 
properties. There are some additives that act by preventing the entry of formation fluids after placing the cement slurry blocking the cement slurry matrix in the setting process. Other alternatives include creating cement slurry volume expansion due to a gas release chemical reaction or generating foam if gas gets in cement slurry matrix.

\section{RHEOLOGY}

The main factors affecting rheology are: solid volumetric concentration; liquid characteristics (viscosity and density among others), and temperature. When the solids concentration is greater, interaction begins to occur between the particles and the rheological behavior is no longer Newtonian. In this case, other characteristics also affect the rheology: particle physical characteristics (i.e. size distribution, density, shape, specific surface area, roughness) and type of interaction between particles (repulsion and attraction).

\section{MATERIALS AND METHODS}

The methodology developed in this work comprises the following steps and is represented by Figure 2 .

- Determination of the equation that relates gas bubble position as a function of fluid viscosity and temperature which are time dependent among others fluid and particle parameters;

- Experiment to evaluate the rheological model;

- Experiment to determine the time dependent fluid viscosity behavior using dynamic oscillatory test;

- Experiment to determine the gel strength along the time and, subsequently, the critical time, (time required to reach critical static gel strength from which gas invasion occurs);

- Determination of the model to represent the equation from the time dependent fluid viscosity behavior.

\subsection{Gas bubble expansion}

The hydrostatic pressure exerted by the fluid in a given depth is expressed by Eq. 1 .

$$
P_{h}=\rho_{f} \cdot g \cdot h_{f}
$$

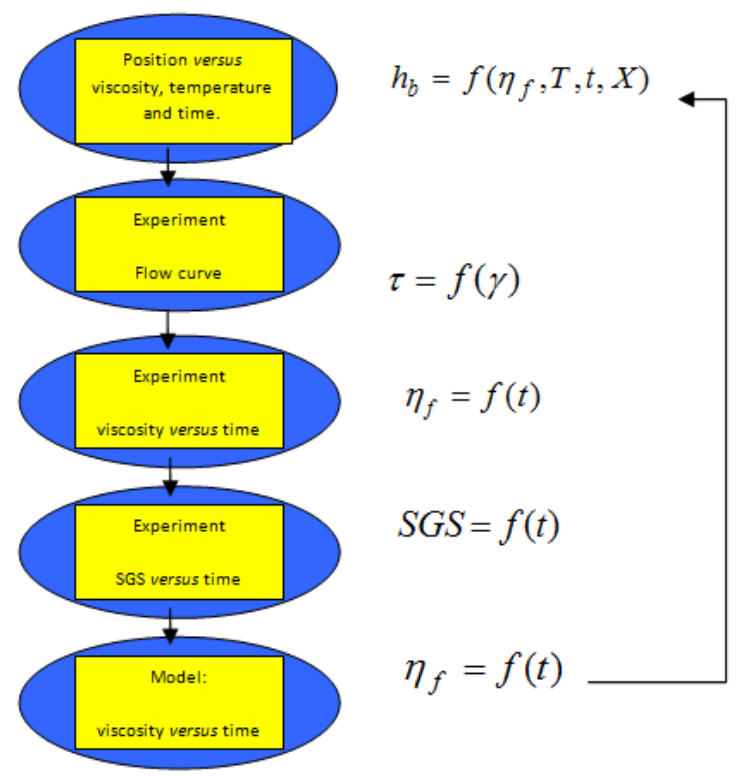

Figure 2. Gas migration evaluation methodology.

Where $P_{h}=$ hydrostatic pressure, $\rho_{f}=$ fluid density, $g=$ gravity acceleration, $h_{f}=$ vertical depth. For a spherical bubble at a given depth, there is an interface between the bubble and the fluid that generates a capillary pressure resulting from the interfacial tension. The capillary pressure (Pellicer et al., 2002) can be defined by Eq. 2:

$$
P_{c}=\frac{2 . \sigma}{r_{b}}
$$

Where $P_{c}=$ capillary pressure, $\sigma=$ surface tension, $r_{b}=$ bubble radius. The total pressure inside the bubble $\left(P_{t}\right)$ is according to Eq. 3:

$P_{t}=P_{h}+P_{c}$

In the application used by this methodology, the capillary pressure did not influence significantly the total pressure when comparing with hydrostatic pressure (deep wells); for this reason this case will neglect it. In addition, on cement slurry composition, antifoam additive is used that reduces the surface tension further reducing the influence of this factor.

According to thermodynamics principles an ideal gas is the one that presents the properties related by the Eq. 4 .

$$
P V=n R T
$$


The mentioned equation (Eq. 4), known as Clausius equation, is defined for any values of pressure $(P)$ and temperature $(T)$, where $V$ is the volume occupied by the gas, $n$ the quantity of gas, and $R$ the universal gas constant (Atkins, 2001).

When the pressure, molar volume and temperature measurements do not allow the relation provided by the Clausius equation within the accuracy of the measurements, gas deviates from ideality. These deviations are small and observed in pure gases and not reactive gas mixtures at low pressures. At room temperature and low pressure it is unlike that the results will present a deviation from ideality, however, as the pressure increase the gas behavior changes.

The evaluation for a real gas behavior can be made by Eq. 5 .

$$
\left(P+a \frac{n^{2}}{V^{2}}\right)(V-n b)=n R T
$$

This equation is known as van der Waals equation of state, where $a$ and $b$ are both characteristic constants of each gas, and depend only on gas composition. According to van Wylen et al. (2003), the real gas behavior deviates from the ideal one at a given pressure and temperature, which can be evaluated by the compressibility factor (Z) defined by Eq. 6 .

$$
Z=\frac{P V}{R T}
$$

Using this methodology, Eq. 4 and 5 compared gas bubble radius using typical oil well scenarios, at various depths, and the average temperature of 50 ${ }^{\circ} \mathrm{C}$, as shown in Figure 3 .

In this case, it was considered the compressibility factor for methane, $\mathrm{Z}=0.82$ (Perry and Green, 1997). The difference of up to $2 \%$ was considered negligible for the purpose of this work. For the development of this methodology it was necessary to obtain an analytical solution for use in bubble position determination. The Eq. 5 is solved only through numeric manipulation, so this paper used Eq. 4 without prejudice to the results.

Evaluating gas condition in two situations, Eq. 7 can be defined as:

$\frac{P_{0} \cdot V_{0}}{Z_{0} T_{0}}=\frac{P \cdot V}{Z T}$

Where $P_{0} ; V_{0} ; Z_{0} ; T_{0}$ are pressure, volume, compressibility factor and temperature at the beginning stage and $P ; V ; Z ; T$ at the final stage. Bubble volume is defined by Eq.8.

$V_{b}=\frac{4}{3} \cdot \pi \cdot r_{b}^{3}$

Substituting and solving Eq. 1 and 8 in Eq.7, it is possible to determine how the bubble radius changes with depth and temperature, thus obtaining Eq. 9.

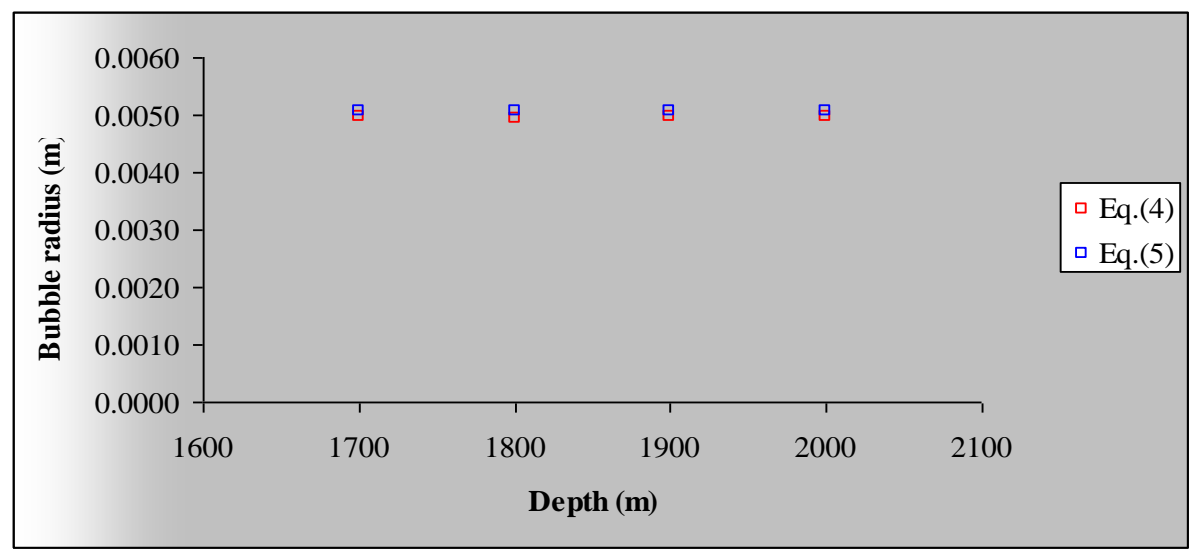

Figure 3. Comparison between equation of state for ideal and real gas. 


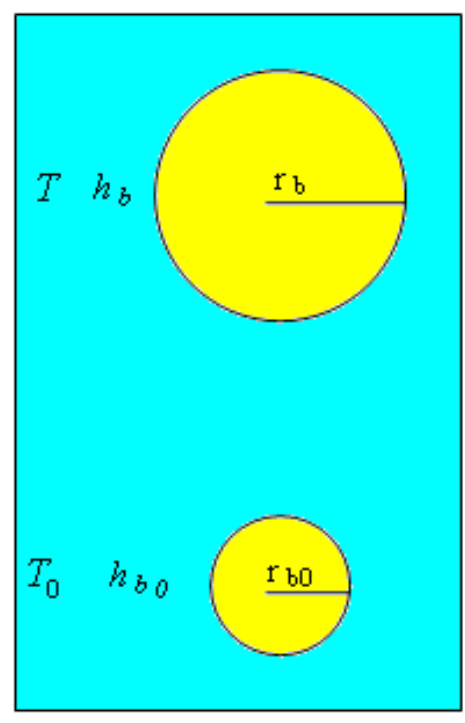

Figure 4. Change in bubble size with depth.

$r_{b}=\sqrt[3]{\frac{h_{b 0}}{h_{b}} \cdot \frac{T}{T_{0}} \cdot \frac{Z}{Z_{0}}} \cdot r_{b 0}$

Being $r_{b o}$ the bubble radius in depth $h_{b o}$ when enters in the well, both defined for a given initial condition, and $r_{b}$ and $h_{b}$ the conditions after a certain time. Figure 4 represents the bubble in its depths.

\subsection{Forces acting on gas bubble}

In the case of a bubble rising through a fluid, it experiences a frictional force $F_{r}$ defined by Eq. 10:

$$
F_{r}=6 . \pi \cdot r_{b} \cdot \eta_{f} \cdot v_{b}
$$

Where, $v_{b}$ is the bubble velocity. The correction for non-Newtonian fluids (Kawase and MooYoung, 1986) is defined by Eq. 11:

$$
F_{r}=6 . \pi \cdot r_{b} \cdot \eta_{f} \cdot X \cdot v_{b}
$$

Where $\eta_{f}$ is the fluid viscosity, $\mathrm{x}$ the deviation factor of friction coefficient defined by Eq. 12:

$$
\mathrm{X}=3^{(3 n-3)^{2}}\left[\frac{-7 n^{2}-4 n+26}{5 n(n+2)}\right]
$$

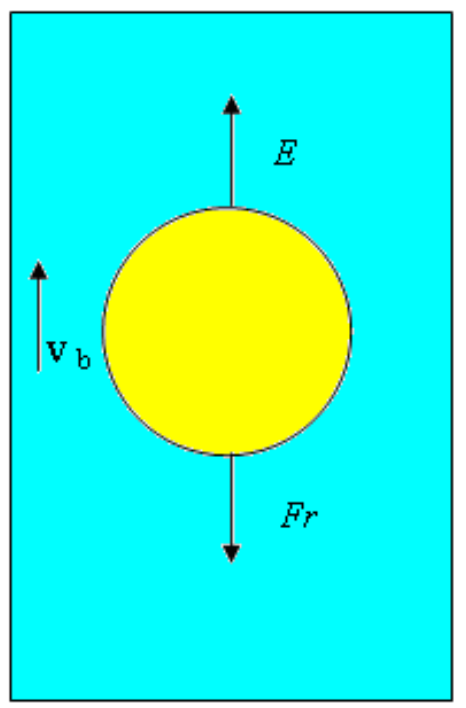

Figure 5. Forces acting on the bubble.

Where $n$ is the index behavior. The second force acting on the bubble is the buoyant force $E$. According to Archimedes' principle, force $E$ is a vertical force from the bottom to up applied at the fluid volume gravity center, displaced equal to weight of the volume of fluid displaced as defined by Eq. 13.

$$
E=\rho_{f} \cdot g \cdot \frac{4}{3} \cdot \pi \cdot r_{b}^{3}
$$

Figure 5 illustrates the forces acting on the bubble.

\subsection{Equation of motion}

Considering the bubble weight negligible and the premise that the particle moves through a viscous fluid in a laminar regime, after a given time it reaches a constant limit velocity and the resulting forces acting on this particle are zero. Assuming that the bubble remains at a steady state, the buoyancy and frictional force are nearly equal and opposite, and the bubble reaches each time the limit velocity although it changes with time (Vermillon, 1975). The forces acting on bubble are as Eq. 14.

$$
E+F_{r}=0
$$

Substituting and solving Eqs. 9, 11 and 13 in Eq. 14 it is obtained Eq. 15. 


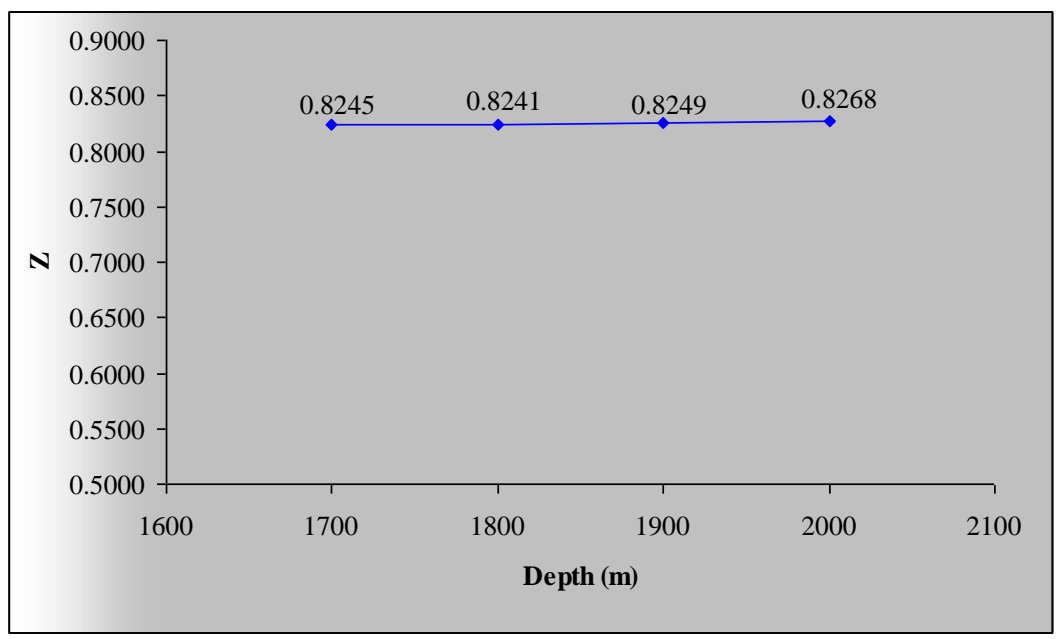

Figure 6. Compressibility factor versus depth.

$v_{b}=-\frac{2 \cdot \rho_{f} \cdot g}{9 \cdot \eta_{f} \cdot X} \cdot\left(\frac{h_{b 0}}{h_{b}} \cdot \frac{T}{T_{0}} \cdot \frac{Z}{Z_{0}}\right)^{2 / 3} . r_{b 0}{ }^{2}$

Separating variables and integrating with the condition that it starts at time $t=0$ the instant the bubble enters the well in depth $h_{b o}$ it is possible determine the bubble position versus time by Eq. 16.

$h_{b t}=\left[h_{b 0}^{5 / 3}-\frac{0.37 \cdot \rho_{f} \cdot g \cdot r_{b 0}{ }^{2}}{\eta_{f} \cdot X} \cdot\left(\frac{h_{b 0} \cdot T \cdot Z}{T_{0} \cdot Z_{0}}\right)^{\frac{2}{3}} \cdot t\right]^{\frac{3}{5}}$

In the case of time dependent viscosity fluids, like the cement slurry, one must determine a function that represents this behavior. This can be obtained through rheological tests followed by an evaluation of a representative function of the model. Considering that the gas will enter the well only some time after the cement slurry placement, the time related to a reduction in hydrostatic pressure that will allow the gas zone pore pressure will overlap the hydrostatic pressure of the well. With this assertion, a correlation between the development of cement slurry viscosity with the gel strength concept was made to determine the critical time; time when the cement slurry reaches a critical static gel strength from which any pressure decay in the well will allow gas invasion.

In this study, the bubble displacement is small, making differential pressure and temperature insufficient to change significantly the compressibility factor. Figure 6 shows the change in compressibility factor versus depth to gas methane at an average temperature of 300K, taking into account the change in hydrostatic pressure.

The temperature changes with well depth and time. It begins at bottom hole circulating temperature and tends to bottom hole static temperature. The circulation temperature in cementing operations is obtained using specific guidelines (API, 1997). In order to automate the test condition determination it was used a computer program that develops tables simulating the cement slurry heating and pressurization after well placement. These conditions are considered during experimental test.

\subsection{Hydrostatic pressure reduction during the transition time}

After the cement slurry placement, there is a reduction in the hydrostatic pressure (Tinsley et al., 1980; Cooke Jr. et al., 1984 and Reddy et al., 2009). This is caused by the volume reduction due to filtration for the adjacent formations and the shrinkage resulting from the cement hydration reactions combined with the pressure restriction caused by cement slurry gelation.

The maximum hydrostatic pressure restriction is related to the resistive force development to cement slurry movement, called static gel strength 
which increases gradually during the transition period. Eq. 17 shows this relationship (Sabins et al., 1982).

$$
\Delta p_{a n}=\frac{4 \cdot S G S \cdot h_{\text {vert.sluryy }}}{\left(D_{\text {well }}-D_{c}\right)}
$$

Where $\Delta p_{\text {an }}$ is pressure drop in the annulus, SGS the static gel strength of cement slurry, $D_{\text {well }}$ the open hole diameter in front of gas zone, $D_{c}$ the casing diameter and $h_{\text {vert.slurry }}$ the cement column height. The volume loss in the bottom of the well causes the cement slurry movement downwards. In response to this motion, a shear stress in the cement slurry against the casing walls is generated and starts to support the cement column (Bonett and Patifis, 1996).

\subsection{Critical static gel strength}

The gel strength value allows the decay of the supporting pressure in the well, equivalent to overbalance pressure until it equals the value of the gas pore pressure. Reaching the critical static gel strength, gas may invade the well. The behavior is defined by Eq. 18.

$S G S_{\text {crit }}=\frac{\Delta p_{o b}\left(D_{\text {well }}-D_{c}\right)}{4 h_{\text {vert.slurry }}}$

Where $S G S_{\text {crit. }}$ is the critical static gel strength and $\Delta p_{o b}$ is the difference between hydrostatic pressure and pore pressure. The smaller the value of critical static gel strength more critical is the possibility of gas invasion during the gelation process. With this critical static gel strength value it is possible to determine the critical time through a gel strength experiment and, then, use that time to determine the initial viscosity of the model.

\subsection{Experimental procedure}

This methodology comprises some experimental tests as mentioned below.

\subsubsection{Cement slurry}

For this work were considered two types of cement slurry ( $A$ and $B$ ) that represent different rheological characteristics affecting mainly gel strength development. The formulation includes various additives especially gas migration controller.

\subsubsection{Rheology}

A flow curve was performed to determine the rheological model and its parameters. The model parameters obtained are used in calculating the deviation factor of the friction coefficient for nonNewtonian fluids.

\subsubsection{Time-dependent viscosity}

The rheological tests simulate real downhole conditions after the cement slurry placement including temperature change. It was conducted at a strain low enough to allow gel growth without breaking it, and the methodology includes schedule and materials to minimize interferences (e.g., grooved geometries to reduce sample slippage).

Dynamic oscillatory rheological tests were conducted to evaluate the time-dependent cement slurry viscosity behavior. First it was performed a strain sweep test with $1 \mathrm{~Hz}$ frequency and strain scan of $10^{-4}$ to $10^{2}$ to determine the linear viscoelastic region. The sample was replaced and held in rotational mode at $10 \mathrm{~s}^{-1}$ for 1 minute to break any gel. Following, the viscosity behavior in dynamic oscillatory mode over time was evaluated with $1 \mathrm{~Hz}$ and strain of $10^{-3}$ (obtained from strain sweep), low enough to allow gel formation. It was then proposed a function representative of the experimental viscosity to be used in the bubble position equation.

\subsubsection{Gel Strength}

Gel strength tests were performed in a MACS II analyzer to evaluate the gel strength behavior along the time. With this test it was possible to obtain the time required to the cement slurry reach critical static gel strength, which is considered the initial condition for the gas migration process as described before.

\section{RESULTS AND DISCUSSION}

\subsection{Rheology}

The model used to characterize the cement slurry was the power law, as shown by Figure 7 . 


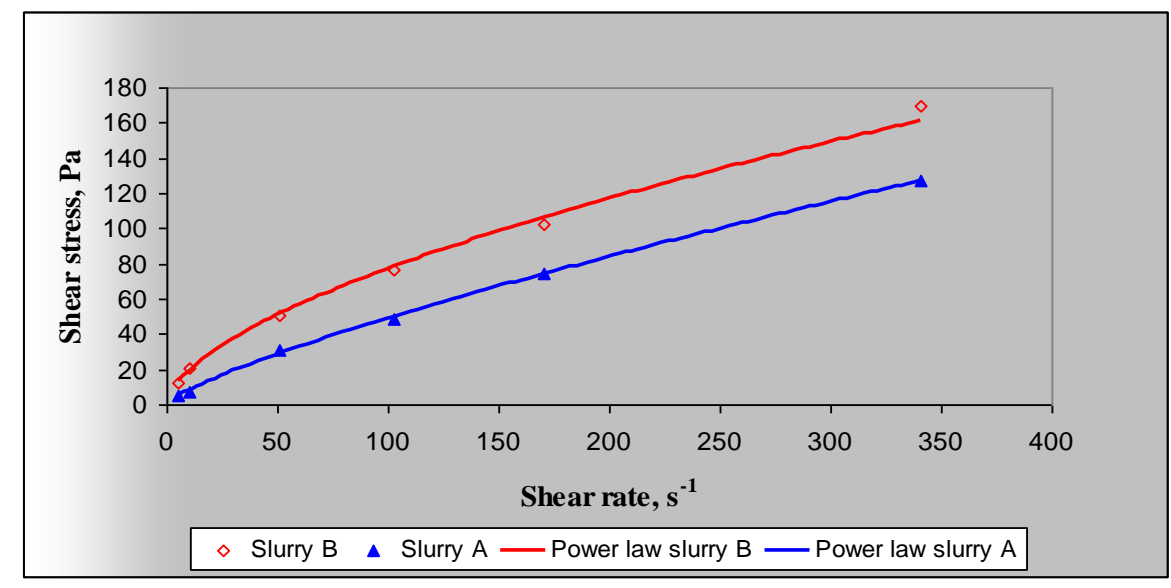

Figure 7. Rheological model for slurries A and B.

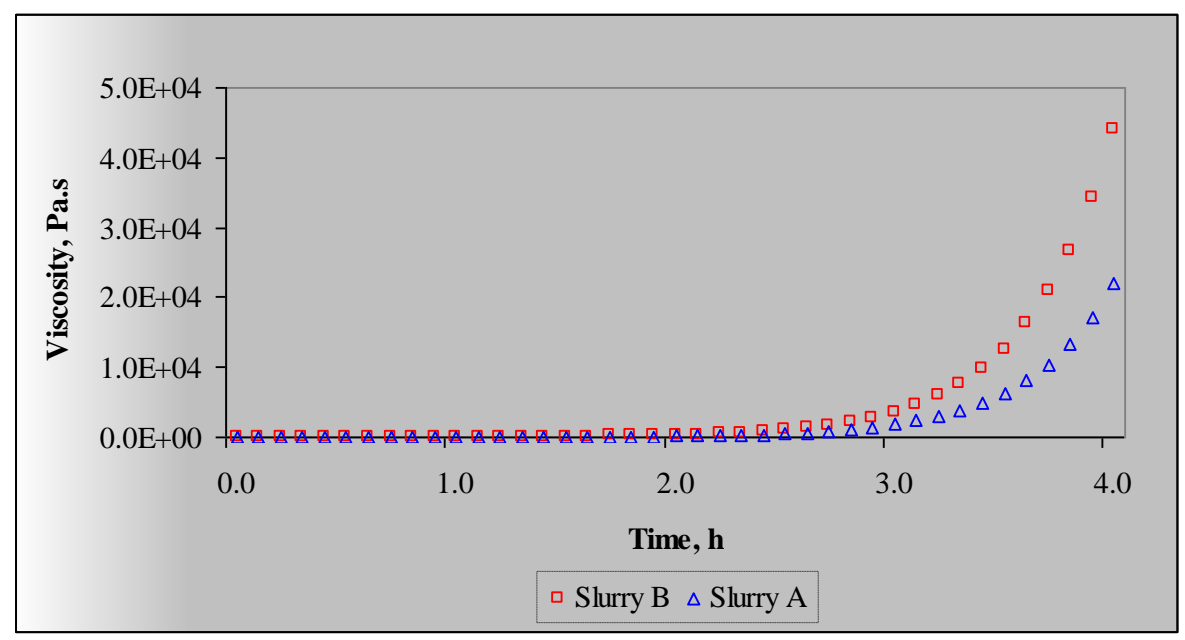

Figure 8. Viscosity changing over time.

A nonlinear regression was made to adjust the model and the behavior index $n$ for cement slurries $A$ and $B$ was obtained.

\subsection{Time dependent viscosity}

Figure 8 shows experimental result for time dependent viscosity behavior for cement slurries $A$ and $\mathrm{B}$.

The behavior observed in the experiment is characteristic of cement slurry, where the slurry remains fluid for some time and, then, quickly gels. The slurry $B$ presents a more intense gelation process than the slurry $A$, justified by the presence of gas migration additive.

\subsection{Gel Strength}

Figure 9 shows the gel strength development along the time for cement slurries $A$ and $B$.

The behavior is similar to that obtained for viscosity, displaying similar characteristics. For the proposed cement project, the $S G S_{\text {crit. }}$ was calculated using Eq. 18 and obtained $70 \mathrm{lb} / 100 \mathrm{ft}^{2}$. So $t_{\text {crit. }}$ was determined as, approximately, $0.4 \mathrm{~h}$ and $0.5 \mathrm{~h}$ for cement slurries $\mathrm{A}$ and $\mathrm{B}$.

\subsection{Proposed model}

A representative model was proposed to explain the experimental viscosity data using Eq. 19. 


$$
\eta_{f}=\eta_{0}+A e^{\frac{t}{k}}
$$

Where $\eta_{0}$ is the initial viscosity obtained from the rheological test for $t_{\text {crit., }} A$ and $k$ the parameters that modify the viscosity growth intensity, and $t$ the elapsed time during the analysis. Figure 10 shows the model application for the experimental results after discarding the data prior to $t_{\text {crit. }}$ resetting the scale to start, at time 0 (zero).

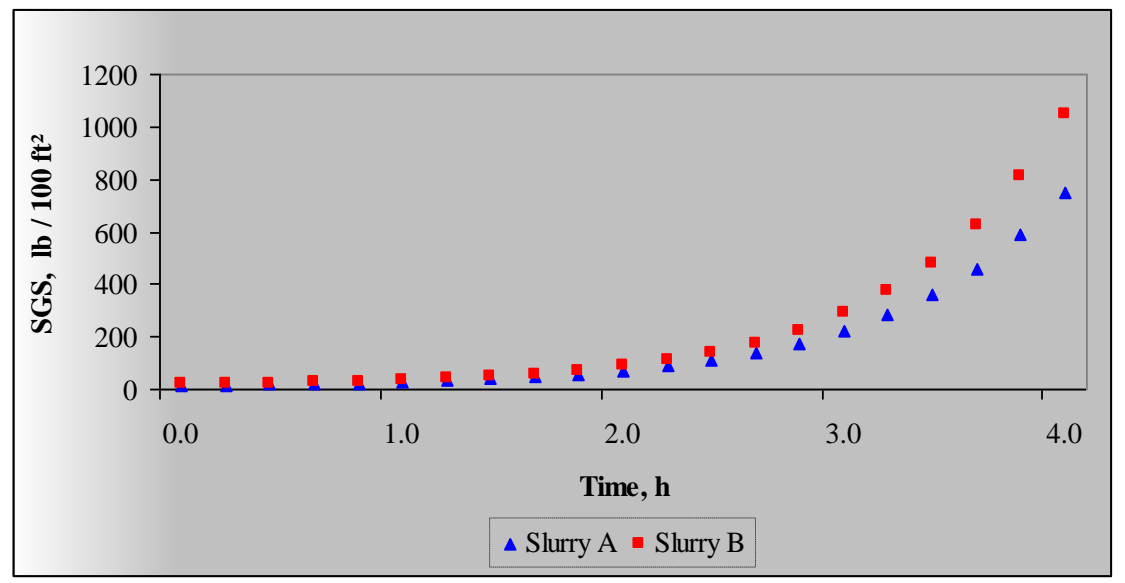

Figure 9. Static gel strength changing over time.

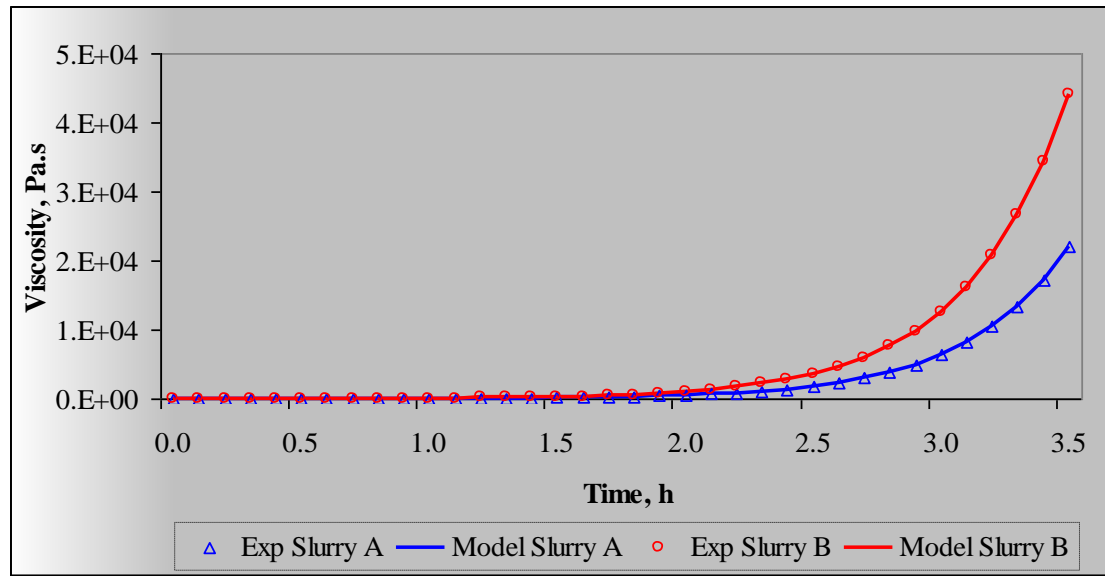

Figure 10. Comparison between experimental and model.

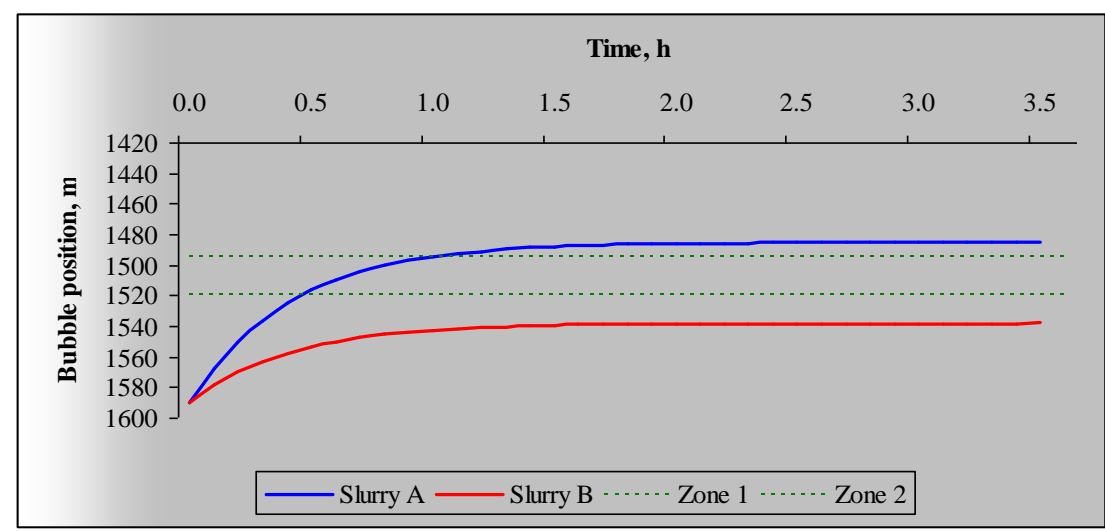

Figure 11. Bubble displacement for cement slurries A and B. 


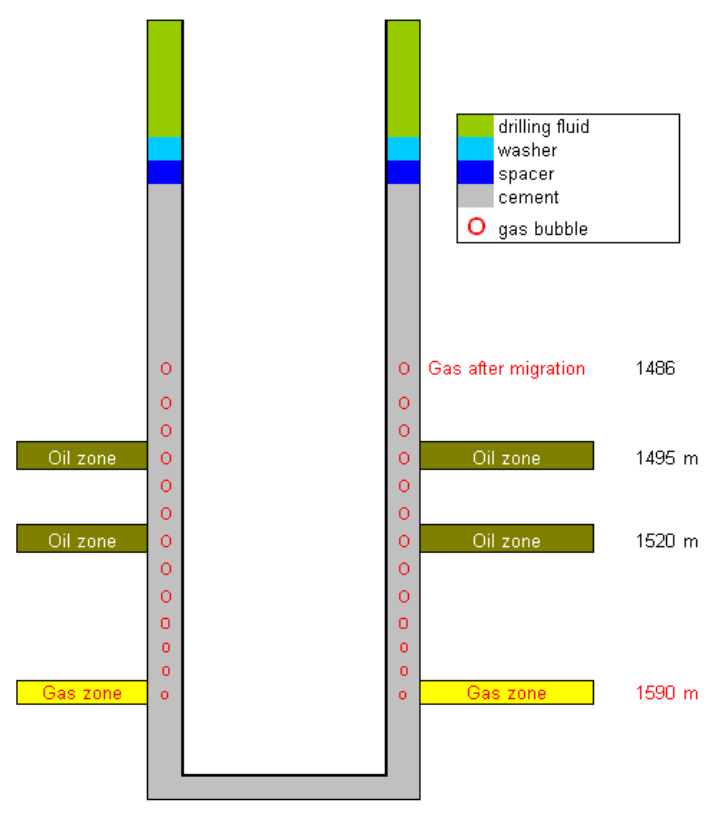

Figure 12. Gas migration using cement slurry A.

\subsection{Case study}

This study considered the depth of the gas zone at $1590 \mathrm{~m}$. It also established the existence of two oil-producing zones at $1495 \mathrm{~m}$ and $1520 \mathrm{~m}$. Figure 11 shows the bubble displacement when using the 2 cement slurries.

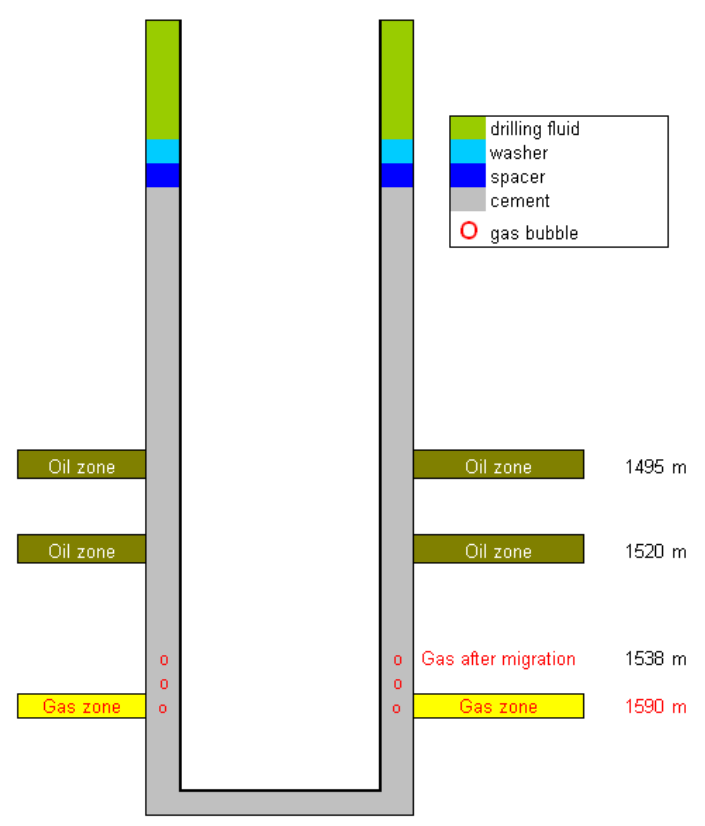

Figure 13. Gas migration using slurry B.
The bubble displacement starts fast in the beginning and reduces as the viscosity increase. Using slurry $A$, gas migration was great enough to damage the hydraulic isolation coming out at $1590 \mathrm{~m}$, reaching $1486 \mathrm{~m}$ and communicating the two interest zones. Using slurry $B$, such phenomenon did not happen, reaching only $1538 \mathrm{~m}$. Figures 12 and 13 show gas migration inside the well using slurries $A$ and $B$.

\section{CONCLUSIONS}

Oil well construction is a complex activity that requires the previous simulation of the operations to ensure the technical and economic project feasibility. It is necessary that the slurries transmit the hydrostatic pressure in order to keep it above the gas zone pressure. This is achieved by keeping the gel strength below the critical value and, after reaching this value, by increasing the viscosity quickly. With the methodology developed in this work, it was possible to evaluate the gas migration criticality and make changes in the slurry design selecting the more appropriate one to the scenario. In this work, slurry B presented insufficient bubble displacement, incapable of affecting the interest zone isolation.

\section{NOMENCLATURE}

$a=$ constant of van der Waals equation, $m V^{2} / L t^{2} m o l^{2}$, atm. $L^{2} / \mathrm{mol}^{2}$

$A=$ parameter that modify the viscosity growth intensity, $m / L t$, Pa.s

$b=$ constant of van der Waals equation, $\mathrm{V} / \mathrm{mol}, 10$ ${ }^{2} \mathrm{~L} / \mathrm{mol}$

$D_{c}=$ casing diameter, $L, m$

$D_{\text {well }}=$ open hole diameter $, L, m$

$E=$ buoyant force, $\mathrm{mL} / \mathrm{t}^{2}, \mathrm{~N}$

$F_{r}=$ friction force, $m L / t^{2}, N$

$g=$ gravity acceleration, $L / t^{2}, \mathrm{~m} / \mathrm{s}^{2}$

$h_{b}=$ depth of the bubble after certain time, $L, m$

$h_{b 0}=$ depth when bubble enters in the well, $L, m$

$h_{f}=$ vertical depth, $L, m$

$h_{\text {vert. slurry }}=$ cement column height, $L, m$

$k=$ parameter that modify the viscosity growth intensity, $t, h$

$n=$ index behavior, dimensionless

$n=$ mols number, $\mathrm{mol}$ 
$P_{h}=$ hydrostatic pressure, $m / L t^{2}, p s i$

$P_{t}=$ total pressure, $m / L t^{2}, p s i$

$P=$ pressure at initial time, $m / L t^{2}, p s i$

$P_{c}=$ capillary pressure, $m / L t^{2}, p s i$

$P_{0}=$ pressure at initial time, $m / L t^{2}, p s i$

$r_{b}=$ bubble radius, $L, m$

$r_{b o}=$ bubble radius at initial time, $L, m$

$R=$ gases universal constant, $\mathrm{mV} / \mathrm{mol}$.T.Lt ${ }^{2}$, atm.l/mol.K

$S G S=$ static gel strength, $m / L t^{2}, l b f / 100 f^{2}$

$S G S_{\text {crit. }}=$ critical static gel strength, $\mathrm{m} / \mathrm{Lt}^{2}, \mathrm{lbf} / 100 \mathrm{ft}^{2}$

$t=$ elapsed time during the analysis, $t, s$

$v_{b}=$ bubble velocity, $L / t, \mathrm{~m} / \mathrm{s}$

$V=$ volume at final time, $V, m^{3}$

$V_{0}=$ volume at initial time, $V, m^{3}$

$T=$ temperature at final time, $T,{ }^{\circ} \mathrm{C}$

$T_{0}=$ temperature at initial time, $T,{ }^{\circ} \mathrm{C}$

$X=$ deviation factor of friction coefficient,

dimensionless

$Z=$ compressibility factor for an initial condition,

dimensionless

$Z_{0}=$ compressibility factor for a final condition,

dimensionless

$\Delta p_{a n}=$ pressure drop in the annulus, $m / L t^{2}, p s i$

$\Delta p_{o b}=$ overbalance pressure, $m / L t^{2}, p s i$

$\eta_{0}=$ initial viscosity, $m / L t$, Pa.s

$\eta_{f}=$ fluid viscosity, $m / L t$, Pa.s

$\rho_{f}=$ fluid density, $\mathrm{m} / \mathrm{L}^{3}, \mathrm{~kg} / \mathrm{m}^{3}$

$\sigma=$ surface tension, $m / t^{2}, \mathrm{~N} / \mathrm{m}$

\section{ACKNOWLEDGEMENTS}

The authors are grateful for the support received from PUC University rheology group and Cement Laboratory from CENPES/Petrobras.

\section{REFERENCES}

API RP10B. Recommended Practice for Testing Well Cements. 22 ${ }^{\text {nd }}$ Edition, 1997.

Atkins, P.; Jones, L. Princípios de química: questionando a vida moderna e o meio ambiente. Trad. Ignez Caracelli. Porto Alegre: Bookman, 2001. (in Portuguese).

Bonett, A; Patifis, D. Getting to the root of gas migration. Oilfield Review, Elsevier 36-49, Spring. 1996.
Cheung, P. R.; Beirute, R. M. Gas Flow in Cements. Journal of Petroleum Technology, v. 37 (6), p. 1041-1048, 1985.

http://dx.doi.org/10.2118/11207-PA

Christian, W. W.; Chatterji; J.; Ostroot; G. W. Gas leakage in primary cementing - A field study and laboratory Investigation. Journal of Petroleum Technology, v. 28 (11), p. 1361-1369, 1976. http://dx.doi.org/10.2118/5517-PA

Cooke Jr., C. E.; Kluck, M. P.; Medrano, R. Annular pressure and temperature measurements diagnose cementing operations. Journal of Petroleum Technology, v. 36 (12), p. 2181-2186, 1984. http://dx.doi.org/10.2118/11416-PA

Kawase, Y.; Moo-Young, M. Approximate solutions for power-law fluid flow past a particle at low Reynolds numbers. Journal of Non-Newtonian Fluid Mechanics, v.21(2), p. 167-177, 1986. http://dx.doi.org/10.1016/0377-0257(86)80034-9

Nelson, E.; Guillot, D. Well Cementing. Texas: Schlumberger Educational Services, $2^{\text {nd }}$ Edition, 2006.

Pellicer, J.; Morales, G. V.; Hernández, M. J. On the demonstration of the Young-Laplace equation in introductory physics courses. Departamento de Termodinámica, Facultad de Física, Universidad de Valencia, Burjassot, Spain. 2002.

Perry, R. H.; Green, D. W. Perry's Chemical Engineers' Handbook. 7th Edition. McGraw-Hill. 1997.

Reddy, B. R.; Ying, X.; Ravi, K.; Gray, D.; Pattillo, $P$. D. Cement-shrinkage measurement in oilwell cementing - A comparative study of laboratory methods and procedures. SPE Drill \& Compl. SPE 103610-MS. 2009.

Rocha, J. M. S. Estudo da migração de gases em pastas de cimento para uso em poços de petróleo. Dissertação de Mestrado (Ciências da Tecnologia de Processos Químicos e Bioquímicos). Escola de Química, Universidade Federal do Rio de Janeiro. 2010. (in Portuguese).

Sabins, F. L.; John M. T.; David L. S. Transition time of cement slurries between the fluid and set state. Society of Petroleum Engineers Journal, v. 22 (6), p. 875-882, 1982.

http://dx.doi.org/10.2118/9285-PA 
Tinsley, J. M.; Miller, E. C.; Sabins, F. L.; Sutton D. L. Study of factors causing annular gas flow following primary cementing. Journal of Petroleum Technology, v. 32 (8), p. 1427-1437, 1980.

http://dx.doi.org/10.2118/8257-PA

van Wylen, G.; Sonntag, R.; Borgnakke, C. Fundamentos da Termodinâmica Clássica. São Paulo: Editora Edgard Blücher Ltda., tradução da 4a Edição Americana, 2003. (in Portuguese).
Vermillon R. A look at some rising bubbles. American Journal of Physics, 43 (2), p. 177-179, 1975. http://dx.doi.org/10.1119/1.9885 